\title{
Comment on "Using groundwater age and hydrochemistry to understand sources and dynamics of nutrient contamination through the catchment into Lake Rotorua, New Zealand" by Morgenstern et al. (2015)
}

\author{
Jonathan M. Abell ${ }^{1}$, David P. Hamilton ${ }^{2}$, and Christopher G. McBride ${ }^{2}$ \\ ${ }^{1}$ Ecofish Research Ltd., 1220-1175 Douglas Street, Victoria, BC, Canada \\ ${ }^{2}$ Environmental Research Institute, University of Waikato, Private Bag 3105, Hamilton 3240, New Zealand \\ Correspondence to: Jonathan M. Abell (jmabell01@gmail.com)
}

Received: 23 September 2015 - Published in Hydrol. Earth Syst. Sci. Discuss.: 13 October 2015

Revised: 26 April 2016 - Accepted: 18 May 2016 - Published: 20 June 2016

\begin{abstract}
This comment addresses a key conclusion in the paper entitled "Using groundwater age and hydrochemistry to understand sources and dynamics of nutrient contamination through the catchment into Lake Rotorua, New Zealand" by Morgenstern et al. (2015). The authors analyse hydrochemistry data and conclude that "the only effective way to limit algae blooms and improve lake water quality in such environments is by limiting the nitrate load". We undertook the crucial task of examining this conclusion because it contradicts the current strategy of limiting both phosphorus and nitrogen loads to the lake, supported by a multi-million dollar programme of action. Following careful consideration, we believe that the conclusion is invalid and outline four reasons to support our assessment. Our comments do not relate to the methodology or results that are presented by Morgenstern et al. (2015), and we recognise that their paper makes an otherwise highly valuable contribution to understanding hydrochemical processes in the catchment.
\end{abstract}

\section{Comment}

Morgenstern et al. (2015; hereafter referred to as "the authors") report a detailed study of the hydrochemistry of Lake Rotorua: a large, volcanically formed lake in the Taupo Volcanic Zone in New Zealand. The lake is nationally iconic and has been the subject of a major restoration programme over recent decades to address water quality issues associ- ated with eutrophication (Parliamentary Commissioner for the Environment, 2006). The authors present water chemistry data for $\sim 100$ sites (springs, wells and streams) throughout the catchment. Variables measured included nutrient concentrations (e.g. $\mathrm{PO}_{4}^{3-}$ and $\mathrm{NO}_{3}^{-}$) and concentrations of chemical tracers of water age. Output from a mixing model, supported by additional water chemistry data, was used to estimate water age based on mean residence times (MRTs) for major stream inflows to the lake, which reflect transit times through groundwater aquifers. Nutrient concentration data were analysed to provide understanding about groundwater processes and the relative importance of anthropogenic and geological sources.

The paper provides a major and important contribution to understanding groundwater processes in the lake catchment. The authors' contributions are particularly significant due to the dominance of groundwater-derived baseflow in stream inflows, resulting in the lake being highly influenced by groundwater inputs, relative to lakes in general (Baisden, 2016). From an applied perspective, accurate MRT estimates are vital for understanding the temporal response of lake water quality to changes in management practices related to nutrient sources such as pastoral land. Furthermore, the relationships derived between water age and nutrient concentration help lake managers to quantify loads "to come", as groundwater chemistry changes in a lagged response to changes in land use practices. Such knowledge is important to help lake managers to better anticipate ecosystem responses, which has been identified as vital to prevent eco- 
logical decline when managing dynamic ecosystems such as Lake Rotorua (Mueller et al., 2015).

Of importance to managing the lake is the knowledge that geological sources contribute to naturally elevated concentrations of $\mathrm{PO}_{4}^{3-}$ in the catchment, both in groundwater and in surface waters that receive high groundwater inputs. This reflects the naturally high phosphorus $(\mathrm{P})$ concentrations of the rhyolitic pumice and ignimbrite that are an important component of the geology of the wider Taupo Volcanic Zone which, coupled with low calcium concentrations, result in relatively high baseline $\mathrm{PO}_{4}^{3-}$ concentrations in groundwater (Timperley, 1983). Consequently, at the national scale, streams draining catchments with such acidic volcanic geology have higher baseline (i.e. natural) $\mathrm{PO}_{4}^{3-}$ concentrations than comparable streams that drain different geologies (McDowell et al., 2013). The authors demonstrate this occurrence very convincingly for the Lake Rotorua catchment in Fig. 7a of their paper; this figure shows a strong positive correlation between MRT and groundwater $\mathrm{PO}_{4}^{3-}$ concentrations, with a maximum MRT of $\sim 170$ years (ignimbrite formation) corresponding to a maximum $\mathrm{PO}_{4}^{3-}$ concentration of $\sim 0.1 \mathrm{mg} \mathrm{PL}^{-1}$. Combined with MRT estimates, the authors use this evidence of high $\mathrm{PO}_{4}^{3-}$ concentrations in "old" groundwater to support the statement that "groundwater chemistry and age data show clearly the source of nutrients that cause lake eutrophication, nitrate from agricultural activities and phosphate from geologic sources". Consequently, the authors conclude that to manage eutrophication symptoms, lake managers should not control $\mathrm{P}$ inputs to the lake and should only focus on limiting nitrogen $(\mathrm{N})$ loads, stating three times that "the only effective way to limit algae blooms and improve lake water quality in such environments is by limiting the nitrate load".

This conclusion by the authors contradicts the current approach to managing water quality in Lake Rotorua that is based on a strategy of dual control of $\mathrm{N}$ and $\mathrm{P}$ (BoPRC, 2004; BoPRC et al., 2009; Burns et al., 2009), founded on the results of research conducted on the lake over several decades (e.g. Fish, 1975; Rutherford et al., 1989; Burger et al., 2007). This strategy of dual nutrient control is supported by a multi-million dollar publicly funded restoration programme, with statutory instruments now in place to help achieve load reduction targets (Parliamentary Commissioner for the Environment, 2006; Burns et al., 2009). Specifically, these instruments comprise a set of rules enforced by regional government to manage terrestrial $\mathrm{N}$ and $\mathrm{P}$ export to water, designed to ensure that current export rates do not exceed benchmarks defined for specific land use activities (BoPRC et al., 2012). These benchmarks reflect targets for maximum $\mathrm{N}\left(435 \mathrm{tN} \mathrm{yr}^{-1}\right)$ and $\mathrm{P}\left(37 \mathrm{tPyr}^{-1}\right)$ loads that have been set for the lake, based on a non-statutory lake action plan (BoPRC et al., 2009) to achieve desirable water quality. The water quality target is defined using a trophic level index (TLI), which is a metric that has been designed using data for
New Zealand lakes (Burns et al., 1999). The TLI is derived from equally weighted scaled measurements of total $\mathrm{N}$ concentration, total P concentration, chlorophyll $a$ concentration (a proxy for phytoplankton biomass), and Secchi depth (a measure of water clarity). The TLI target for Lake Rotorua is 4.2 (BoPRC et al., 2009), which is at the lower end of the eutrophic category (4.0-5.0; Burns et al., 1999). Since the mid2000s, there has been a general decline in the TLI of Lake Rotorua (i.e. improved water quality; Abell et al., 2012a; Smith et al., 2016), and the annual average TLI reached the lake target in 2012 and 2014 (BoPRC et al., 2015a). A significant factor contributing to recent improvement in water quality is the action of dosing aluminium sulfate (alum) to two stream inflows, initiated in one inflow in 2006 and the second in 2010 (Hamilton et al., 2015). This action has reduced dissolved $\mathrm{P}$ concentrations in the two treated streams, while excess alum has also contributed to further reducing ambient dissolved $\mathrm{P}$ concentrations in the lake to a level where $\mathrm{P}$ limitation of phytoplankton biomass accumulation is likely to occur (Hamilton et al., 2015). Despite this success, there are long-term risks associated with the technique (Tempero, 2015) and there is recognition that, although such geoengineering solutions can be a useful component of a wider range of restoration actions, they are not a substitute for long-term sustainable reductions in nutrient loads from the wider catchment (Abell et al., 2012b; MacKay et al., 2014).

Clearly, the authors' support for a focus on $\mathrm{N}$ control calls into question the soundness of the current dual nutrient control strategy. If valid, their conclusion warrants major revision of the current approach to managing water quality in this nationally important lake. After carefully considering the basis of their conclusion, we have identified four main reasons why we believe that the specific conclusion recommending $\mathrm{N}$-only control is invalid.

1. We agree that high phosphate concentrations in "old" groundwater contribute to phosphate concentrations in many stream inflows to the lake that are relatively high from a biological perspective. However, we disagree that this fact means that $\mathrm{P}$ does not have potential to limit primary productivity in the lake, as implied in the final two paragraphs of Sect. 4.4.

The authors imply that $\mathrm{P}$ control is redundant, partly based on the observation that natural $\mathrm{P}$ sources result in groundwater inputs to the lake having "high $\mathrm{PO}_{4}$ concentrations, well above the threshold for primary algae production of ca. $0.03 \mathrm{mg} \mathrm{L}^{-1}$ total phosphate (Dodds, 2007)". Firstly, it is not clear what the "threshold for primary algae production" refers to; the only reference to this concentration in the cited reference relates to a boundary between mesotrophic and eutrophic lakes defined by Nürnberg (1996). Nevertheless, the key issue here is that the authors have considered only nutrient sources and have neglected to consider nutrient sinks in drawing their conclusion. In-lake processes typ- 

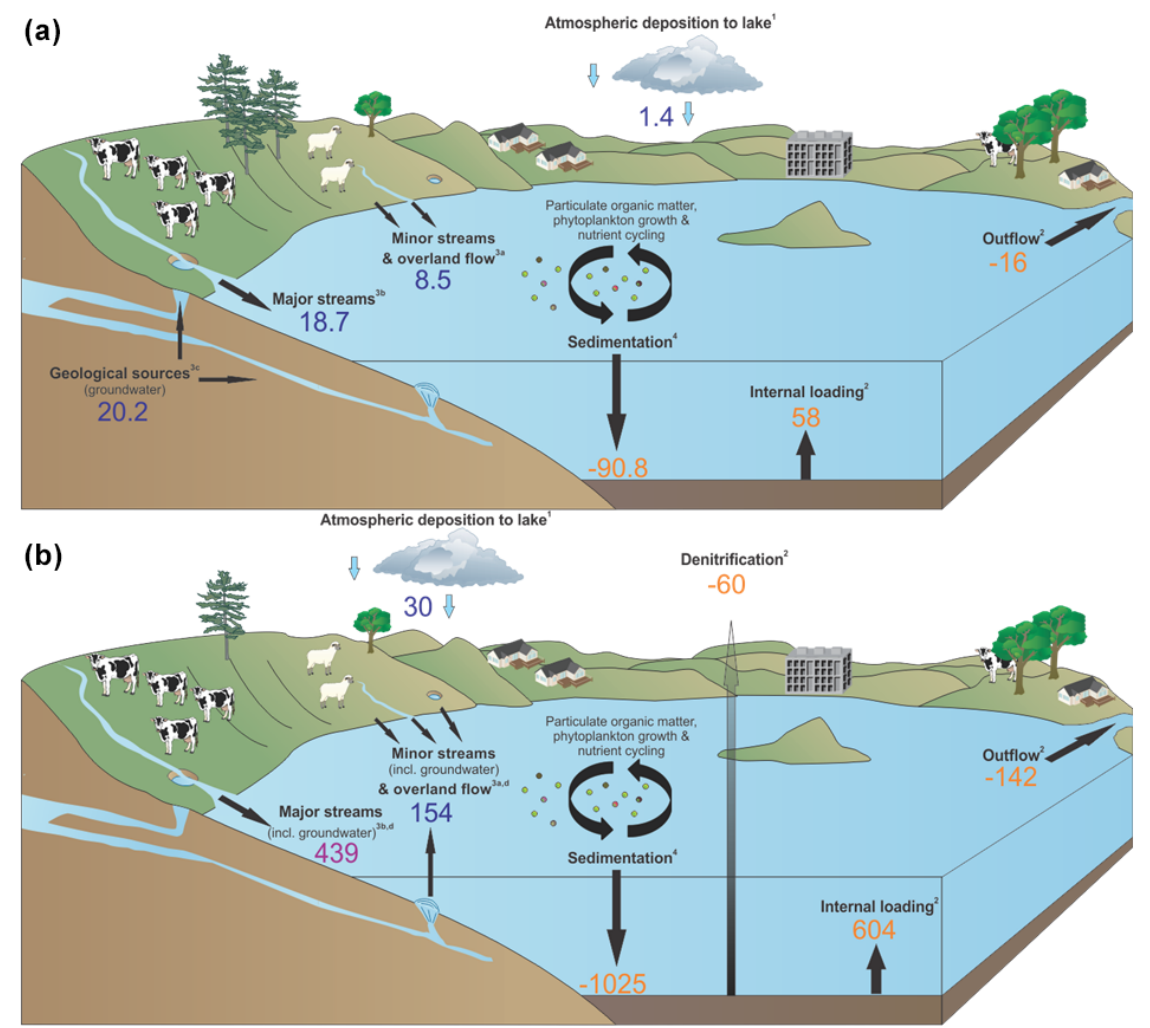

1. Hoare (1980)

2. Output from the DYRESM-CAEDYM lake model of Abell et al. (2015)

3. Catchment loads of $\mathrm{N}$ and $\mathrm{P}$, as summarised in Abell et al. (2015)

a) Load based on residual term in water balance and volumetric average concentration measured in major stream inflows. Thus, this component represents multiple sources and uncertainty is high.

b) Increasing particulate nutrient concentrations at high discharge ('storm loads') were modelled for only three of the nine major streams. Thus, total storm loads to the lake are likely to be underestimated.

c) The proportion of catchment inputs attributable to geological sources in groundwater was estimated by Tempero et al. (2016). Groundwater P loads were estimated for individual sub-catchments based on estimated hydraulic loads and $\left[\mathrm{PO}_{4}-\mathrm{P}\right]$ estimated from relationship between $\left[\mathrm{PO}_{4}-\mathrm{P}\right]$ and mean residence time reported by Morgenstern et al. (2015).

d) Includes $\mathrm{N}$ transported to major streams from surface and groundwater sources.

4. Calculated as the residual of the mass balance for the whole lake and catchment

Figure 1. Catchment and lake nutrient budgets for Lake Rotorua for (a) phosphorus (P) and (b) nitrogen (N). Units are tonnes of total nutrient (P or N) per year. Values are annual averages for the period 2007-2014 when aluminium sulfate was applied to two lake inflows. Values in purple are based on annual means of observations, orange are derived from outputs from a 1-D lake model, and blue are estimated using other methods (see notes). Calculation methods differ from those used to measure progress towards lake action plan targets.

ically reduce ambient lake surface water concentrations of $\mathrm{PO}_{4}^{3-}$ to levels much lower than those in the main inflowing streams; one such important process is biological uptake and subsequent sedimentation of particulate organic material (Fig. 1). Thus, while concentrations of $\mathrm{PO}_{4}^{3-}$ in inflows may exceed some defined threshold at which $\mathrm{P}$ does not limit net phytoplankton production (based on other limiting factors), concentrations in the lake may be considerably below this threshold, with phytoplankton biomass accumulation in the lake P-limited at times. To illustrate, monthly mon- itoring data for the last eight complete years $(2007-$ 2014; BoPRC, 2015b) show that median $\mathrm{PO}_{4}^{3-}$ concentrations in the nine major stream inflows ranged from 0.017 to $0.094 \mathrm{mg} \mathrm{PL}^{-1}$. By contrast, median surface water $\mathrm{PO}_{4}^{3-}$ concentration measured at two central lake sites was $0.002 \mathrm{mg} \mathrm{PL}^{-1}$ - an order of magnitude lower (range of values $=<0.001-0.017 \mathrm{mg} \mathrm{PL}^{-1}$, 95th percentile $=0.006 \mathrm{mg} \mathrm{PL}^{-1}$ ). Such concentrations are generally below levels at which $\mathrm{PO}_{4}^{3-}$ concentrations have the potential to suppress phytoplankton growth rates ( $\sim 0.003 \mathrm{mg} \mathrm{PL}^{-1}$; Reynolds, 2006) and, depending on 
the availability of other resources such as light and $\mathrm{N}$, these concentrations have the potential to limit phytoplankton biomass accumulation. Indeed, phytoplankton biomass accumulation in the lake has been shown experimentally to be limited at times by $\mathrm{P}$, either in isolation or in conjunction with $\mathrm{N}$ (Burger et al., 2007; Smith et al., 2016). These observations are consistent with the view more generally that co-limitation of phytoplankton biomass accumulation by both $\mathrm{N}$ and $\mathrm{P}$ is commonplace in freshwater ecosystems (Elser et al., 2007).

To provide context, we present lake and catchment $\mathrm{P}$ and $\mathrm{N}$ budgets in Fig. 1. Figure 1a illustrates the significant contribution of the authors' work, as their results have been used to estimate the magnitude of the $\mathrm{P}$ load via deep groundwater springs $\left(\sim 20.2 \mathrm{t} \mathrm{Pyr}^{-1}\right)-\mathrm{a}$ component that could not previously be resolved. As the authors describe, this component represents $\mathrm{P}$ from natural geologic sources and makes a major contribution to the overall lake and catchment P budget. Nonetheless, Fig. 1a also highlights the significant contributions of other $\mathrm{P}$ sources that should also be considered alongside groundwater springs when examining $\mathrm{P}$ cycling in the catchment. These other sources include internal loading from the bed of the lake (Burger et al., 2008), dissolved $\mathrm{P}$ transported in throughflow from agricultural land, and particulate $\mathrm{P}$ transported in overland flow, particularly during rain storms (Abell et al., 2013). Thus, while detailed study of individual components of the cycle is important to improve understanding, the range of major nutrient fluxes should be considered when developing catchment-scale lake management policy, not just those that relate to groundwater.

2. The authors' conclusion that N-only control should be adopted is based on their inference that natural P loads greatly dominate those from anthropogenic sources, and the fact that anthropogenic loads are much easier to reduce than natural loads 1 . They state that "the high phosphate load to the lake via groundwater is natural", and "there is a constantly high $\mathrm{PO}_{4}$ load reaching the lake via all streams" (Sect. 4.4). We disagree with the implication that anthropogenic sources of $\mathrm{P}$ to the lake are negligible. As we describe above, $\mathrm{P}$ inputs to Lake Rotorua have the potential to contribute to eutrophication, and we maintain that there is considerable scope to manage $\mathrm{P}$ from anthropogenic sources to support lake water quality objectives.To support this, we note that P loads in specific catchment streams have been shown to decline significantly in response to implementation of best

\footnotetext{
${ }^{1}$ Although we note that the action of dosing aluminium sulfate to stream inflows since 2006 reduces stream $\mathrm{PO}_{4}^{3-}$ concentrations regardless of source and has had marked success in supporting work to achieve lake water quality objectives (Hamilton et al., 2015; Smith et al., 2016).
}

management practices (e.g. riparian planting) designed to reduce $\mathrm{P}$ loss from agricultural land, thus implying that significant reductions in $\mathrm{P}$ load to the lake can be achieved by controlling anthropogenic sources (e.g. $27 \%$ reduction in particulate $\mathrm{P}$ load and $26 \%$ reduction in $\mathrm{PO}_{4}^{3-}$ load; Williamson et al., 1996). Crucially, lake water quality has been clearly shown to respond to such changes in anthropogenic P loads (Rutherford et al., 1989, 1996), highlighting the importance of managing $\mathrm{P}$ in conjunction with $\mathrm{N}$ to achieve lake water quality objectives. In drawing conclusions regarding nutrient management based on data regarding $\mathrm{PO}_{4}^{3-}$ in groundwater, a key consideration that has been overlooked is that $\mathrm{P}$ transport by overland-flow processes is often dominant to sub-surface transport (e.g. McDowell et al., 2003). As the authors indicate (Sect. 4.4), the local soils have a high capacity to retain $\mathrm{PO}_{4}^{3-}$ from anthropogenic sources. However, while this may limit $\mathrm{PO}_{4}^{3-}$ concentrations in "young" groundwater, this does not exclude episodic $\mathrm{P}$ transport to waterways following high rainfall. Indeed, stream-water quality monitoring highlights spikes in total $\mathrm{P}$ concentrations during stormflow periods (Abell et al., 2013), while laboratory experiments highlight the potential for farmland sediments that are enriched with particulate $\mathrm{P}$ to be transported in overland flow and contribute soluble P to Lake Rotorua (Peryer-Fursdon et al., 2015).

Recently, the authors' results have been used to estimate the relative proportion of the external $\mathrm{P}$ load from each lake sub-catchment that originates from anthropogenic sources (Tempero et al., 2016). These estimates were derived by subtracting estimated natural loads from current measured loads. Natural loads correspond to baseline conditions prior to human presence in the catchment and were estimated as the sum of baseline groundwater loads and baseline surface loads. Baseline groundwater loads were estimated using the authors' results, while baseline surface loads were estimated using baseline concentrations estimated by McDowell et al. (2013). For the whole lake catchment, the study estimated that $48 \%$ of the total P load and $22 \%$ of the dissolved reactive $\mathrm{P}$ load originate from anthropogenic sources. Thus, although these values are likely to be relatively low for eutrophic lakes generally, these results highlight that an appreciable proportion of the total $\mathrm{P}$ load is from anthropogenic sources. In particular, these results highlight the importance of controlling particulate P loads transported in surface water, e.g. associated with soil erosion on farmland. Such loads were not considered by Morgenstern et al. (2015) when drawing conclusions about the most appropriate catchment-scale policy to manage water quality.

3. We believe that a strategy of only "limiting the nitrate load" would unduly inhibit the timelines over which 
lake water quality objectives could be achieved. This is due to the unresponsive nature of catchment nitrate loads, which the authors have effectively demonstrated. The authors' conclusions are based only on consideration of groundwater processes. We maintain that wider consideration of nutrient pools and transport processes (e.g. internal loading and overland flow) leads to the conclusion that dual control of $\mathrm{N}$ and $\mathrm{P}$ is more efficient than focusing solely on controlling nitrate loading to address eutrophication.

The authors' study crucially highlights the long lag times between anthropogenic $\mathrm{N}$ loading to land and subsequent transport to the lake via groundwater transport. For example, Table 2 in the authors' paper shows that the mean residence times (MRTs) of sub-catchments to Lake Rotorua range from 30 to 145 years, thus indicating that there is expected to be a lag of decades on average before groundwater $\mathrm{N}$ loads respond to actions to reduce nitrate leaching from land. Thus, a strategy of focusing only on reducing nitrate loads to the lake would prevent community aspirations of lake water quality from being achieved for some decades.

We recognise that these MRT estimates reflect finerscale spatial variability in groundwater transit times and, therefore, there is potential to achieve more-rapid reductions in groundwater loads by targeting "young" groundwater sources. The authors' results, and further work based on their methods, have potential to provide the detailed scientific understanding necessary to inform such a focused approach to managing nitrate pollution. We support using such detailed knowledge of groundwater pathways to minimise the timeframe over which load reduction targets could be achieved. Nevertheless, the differences in dominant transport mechanisms between $\mathrm{N}$ and $\mathrm{P}$ that we highlight above mean that a strategy of controlling both $\mathrm{N}$ and $\mathrm{P}$ would provide a shorter timescale for achievement of lake water quality objectives than controlling only $\mathrm{N}$ and being tied to long groundwater nitrate transit times. Such a strategy of dual nutrient control therefore provides for greater flexibility in the range of management actions that can be considered for managing nutrient loads (internal and external) to the lake (e.g. see Burns et al., 2009). In addition, the potential for either $\mathrm{N}, \mathrm{P}$, or $\mathrm{N}$ and $\mathrm{P}$ to limit phytoplankton biomass accumulation at times in Lake Rotorua (Burger et al., 2007) means that a focus on controlling both nutrients is expected to be more efficient that controlling only one nutrient (cf. Lewis et al., 2011). Such potential for managing eutrophication symptoms more efficiently and successfully is a key reason why a strategy of dual nutrient control is generally recommended for managing lake water quality in New Zealand (Abell et al., 2010) and more widely (Lewis et al., 2011; Paerl, 2009; Paerl and Otten, 2013).
4. Focusing only on controlling external nitrate loads to the lake is likely to reduce the $\mathrm{N}: \mathrm{P}$ ratio in lake water. This has the potential to promote greater relative abundance of undesirable cyanobacteria in the lake. High abundance of cyanobacteria is generally undesirable due to propensity for some species to produce toxins and form unsightly scums.

Some species of cyanobacteria can use atmospheric $\mathrm{N}$ gas as a partial $\mathrm{N}$ source (i.e. $\mathrm{N}$-fixation), and thus gain a competitive advantage over other phytoplankton species when $\mathrm{N}$ availability in lake water is relatively low, implicit when the N:P ratio is low (Smith, 1983). Potential $\mathrm{N}$-fixing species include those from genera associated with toxin production (e.g. Anabaena; Reynolds, 2006). Multiple studies have demonstrated that conditions which cause low $\mathrm{N}: \mathrm{P}$ in lake water can result in increased dominance of cyanobacteria (Smith, 1983; Nõges et al., 2008; Vrede et al., 2009). Further, a strategy of focusing on nitrate control is expected to result in a low $\mathrm{N}: \mathrm{P}$ ratio coupled with high $\mathrm{P}$ concentrations. These are precisely the conditions that are associated with a high risk of harmful algal blooms: lake surface water total $\mathrm{P}$ concentrations are frequently a strong predictor of cyanobacteria abundance (Smith et al., 1987, 2016), and they are often a better predictor of cyanobacteria dominance than low $\mathrm{N}: \mathrm{P}$ ratio (Dokulil and Teubner, 2000; Downing et al., 2001).

Thus, although the relationship is complex and mediated by factors such as temperature and $\mathrm{P}$ concentrations (Håkanson et al., 2007), a strategy of controlling only nitrate and not $\mathrm{P}$ has the potential to increase the dominance of $\mathrm{N}$-fixing cyanobacteria as a consequence of reduced $\mathrm{N}: \mathrm{P}$ ratios and accompanying high in-lake $\mathrm{P}$ concentrations. Proliferation of such species also has the potential to partly offset any reductions in external $\mathrm{N}$ load (Schindler et al., 2008), and the potential for increased dominance of cyanobacteria is a key reason why a strategy of $\mathrm{N}$-only control has previously been rejected for the lake (Rutherford et al., 1989; BoPRC, 2004) and the non-statutory lake action plan includes the aim to make "phosphorus the key limiting lake nutrient" (BoPRC et al., 2009).

\section{Conclusion}

In closing, we conclude that the results presented by Morgenstern et al. (2015) do not support a rationale of N-only control, and therefore the current strategy of controlling both $\mathrm{N}$ and $\mathrm{P}$ in the catchment of Lake Rotorua should be maintained. Our comment does not relate to the methods or results presented by the authors, and we recognise the very valuable contribution that their detailed work otherwise makes to understanding hydro-chemical processes in the catchment. 
Acknowledgements. We thank Val Smith, an anonymous reviewer, Troy Baisden, and Uwe Morgenstern for providing thoughtful comments on our discussion paper.

Water quality data used to develop the nutrient budgets were provided by Bay of Plenty Regional Council. Hydrological data were provided by the National Institute of Water and Atmospheric Research and Bay of Plenty Regional Council. The authors acknowledge funding from the New Zealand Ministry of Business, Innovation and Employment (UOWX1503; enhancing the health and resilience of New Zealand lakes).

Edited by: A. Ghadouani

\section{References}

Abell, J. M., Özkundakci, D., and Hamilton, D. P.: Nitrogen and phosphorus limitation of phytoplankton growth in New Zealand lakes: Implications for eutrophication control, Ecosystems, 13, 966-977, 2010.

Abell, J., Stephens, T., Hamilton, D., McBride, C., and Scarsbrook, M.: Analysis of Lake Rotorua Water Quality Trends: 2001-2012. Environmental Research Institute Report 10. Client report prepared for Environment Court mediation on the Bay of Plenty Regional Policy Statement. Environmental Research Institute, The University of Waikato, Hamilton, New Zealand, available at: http://www.rotorualakes.co.nz/vdb/document/503 (last access: 19 March 2016), 2012a.

Abell, J. M., Hamilton, D. P., and Paterson, J.: Reducing the external environmental costs of pastoral farming in New Zealand: Experiences from the Te Arawa lakes, Rotorua, Aust. J. Environ. Manage., 18, 139-154, 2012b.

Abell, J. M., Hamilton, D. P., and Rutherford, J. C.: Quantifying temporal and spatial variations in sediment, nitrogen and phosphorus transport in stream inflows to a large eutrophic lake, Environ. Sci. Process. Imp., 15, 1137-1152, 2013.

Abell, J. M., McBride, C. M., and Hamilton, D. P.: Lake Rotorua Wastewater Discharge Environmental Effects Study. ERI Report No. 60. Client report prepared for Rotorua Lakes Council. Environmental Research Institute, Faculty of Science and Engineering, The University of Waikato, Hamilton, New Zealand, available at: http://www.waikato.ac.nz/eri/research/publications (last access: 10 June 2016.), 2015.

Baisden, T.: Interactive comment on "Comment on "Using groundwater age and hydrochemistry to understand sources and dynamics of nutrient contamination through the catchment into Lake Rotorua, New Zealand" by Morgenstern et al. (2015)" by J. M. Abell et al. Hydrol. Earth Syst. Sci. Discuss., 12, C5866-C5871, 2016.

BoPRC (Bay of Plenty Regional Council): A Statement of the Significance of Phosphorus and Nitrogen in the Management of Lakes Rotorua/Rotoiti. Statement prepared by a Water Quality Technical Advisory Group, available at: http://www.boprc.govt. nz/media/34320/TechReports-040101-SignificancePandN.doc last access: 12 August 2015), 2004.

BoPRC (Bay of Plenty Regional Council), Environment Bay of Plenty, Rotorua Lakes Council and Te Arawa Lakes Trust: Lakes Rotorua and Rotoiti Action Plan. Environment Bay of Plenty Environmental Publication 2009/03, Whakatane, 29 pp., 2009.
BoPRC (Bay of Plenty Regional Council), Bay of Plenty Regional Council, Rotorua Lakes Council and Te Arawa Lakes Trust: What is Rule 11?, 4 pp. available at: http://www.rotorualakes. co.nz/vdb/document/136 (last access: 19 March 2016), 2012.

BoPRC (Bay of Plenty Regional Council), Bay of Plenty Regional Council, Rotorua Lakes Council and Te Arawa Lakes Trust: Annual Report 2014-2015, 36 pp., available at: http://www. rotorualakes.co.nz/vdb/document/1370 (last access: 19 March 2016), 2015a.

BoPRC (Bay of Plenty Regional Council): State of the Environment Monitoring Data, provided by: Scholes, P., Environmental Scientist, Bay of Plenty Regional Council, 2015b.

Burger, D. F., Hamilton, D. P., Hall, J. A., and Ryan, E. F.: Phytoplankton nutrient limitation in a polymictic eutrophic lake: community versus species-specific responses, Fund. Appl. Limnol., 169, 57-68, 2007.

Burger, D. F., Hamilton, D. P., and Pilditch, C. A.: Modelling the relative importance of internal and external nutrient loads on water column nutrient concentrations and phytoplankton biomass in a shallow polymictic lake, Ecol. Model., 211, 411-423, 2008.

Burns, N., Rutherford, J. C., and Clayton, J. S.: A monitoring and classification system for New Zealand lakes and reservoirs, J. Lakes Res. Manage., 15, 225-271, 1999.

Burns, N., McIntosh, J., and Scholes, P.: Managing the lakes of the Rotorua District, New Zealand, Lake Res. Manage., 25, 284 296, 2009.

Dodds, W. K.: Trophic state, eutrophication and nutrient criteria in streams, Trends Ecol. Evol., 22, 669-676, 2007.

Dokulil, M. T. and Teubner, K.: Cyanobacterial dominance in lakes, Hydrobiol., 438, 1-12, 2000.

Downing, J. A., Watson, S. B., and McCauley, E.: Predicting cyanobacteria dominance in lakes. Can. J. Fish. Aquat. Sci., 58, 1905-1908, 2001.

Elser, J. J., Bracken, M. E. S., Cleland, E. E., Gruner, D. S., Harpole, W. S., Hillebrand, H., Ngai, J. T., Seabloom, E. W., Shurin, J. B., and Smith, J. E.: Global analysis of nitrogen and phosphorus limitation of primary producers in freshwater, marine and terrestrial ecosystems, Ecol. Lett., 10, 1135-1142, 2007.

Fish, G. R.: Lakes Rotorua and Rotoiti, North Island New Zealand: Their Trophic Status and Studies for a Nutrient Budget. Fisheries Research Bulletin No. 8. Fisheries Research Division, New Zealand Ministry of Agriculture and Fisheries, 1975.

Håkanson, L., Bryhn, A. C., and Hytteborn, J. C.: On the issue of limiting nutrient and predictions of cyanobacteria in aquatic systems, Sci. Total Environ., 379, 89-108, 2007.

Hamilton, D. P., McBride, C. G., and Jones, H. F. E: Assessing the effects of alum dosing of two inflows to Lake Rotorua against external nutrient load reductions: Model simulations for 20012012, Environmental Research Institute Report 49, University of Waikato, Hamilton, 56 pp., available at: http://www.rotorualakes. co.nz/vdb/document/1034 (last access: 19 March 2016), 2015.

Hoare, R. A.: Inflows to Lake Rotorua, J. Hydrol. (NZ), 19, 49-59, 1980.

Lewis, W. M., Wurtsbaugh, W, A., and Paerl, H. W.: Rationale for control of anthropogenic nitrogen and phosphorus to reduce eutrophication of inland waters, Environ. Sci. Tech., 45, 1030010305, 2011.

MacKay, E., Maberly, S. C., Pan, G., Reitzel, K., Bruere, A., Corker, N., Douglas, G., Egemose, S., Hamilton, D. P., Hatton-Ellis, T., 
Huser, B., Li, W., Meis, S., Moss, B., Lürling, M., Phillips, G., Yasseri, S., and Spears, B. M.: Geoengineering in lakes: welcome attraction or fatal distraction?, Inland Waters, 4, 349-356, 2014.

McDowell, R. W., Biggs, B. J. F., Sharpley, A. N., and Nguyen, L.: Connecting phosphorus loss from agricultural landscapes to surface water quality, Chem. Ecol., 20, 1-40, 2003.

McDowell, R. M., Snelder, T. H., Cox, N., Booker, D. J., and Wilcock, R. J.: Establishment of reference or baseline conditions of chemical indicators in New Zealand streams and rivers relative to present conditions, Marine Freshw. Res., 64, 387-400, 2013.

Morgenstern, U., Daughney, C. J., Leonard, G., Gordon, D., Donath, F. M., and Reeves, R.: Using groundwater age and hydrochemistry to understand sources and dynamics of nutrient contamination through the catchment into Lake Rotorua, New Zealand, Hydrol. Earth Syst. Sci., 19, 803-822, doi:10.5194/hess-19-803-2015, 2015.

Mueller, H., Hamilton, D. P., and Doole, G. J.: Response lags and environmental dynamics of restoration efforts for Lake Rotorua, New Zealand, Environ. Res. Lett., 10, 074003, doi:10.1088/1748-9326/10/7/074003, 2015.

Nõges, T., Laugaste, R., Nõges, P., and Tonno, I.: Critical N : PP ratio for cyanobacteria and $\mathrm{N}_{2}$-fixing species in the large shallow temperate lakes Peipsi and Võrtsjärv, North-East Europe, Hydrobiologia, 599, 77-86, 2008.

Nürnberg, G. K.: Trophic state of clear and colored, soft- and hardwater lakes with special consideration of nutrients, anoxia, phytoplankton and fish, Lake Res. Manage., 12, 432-447, 1996.

Paerl, H. W.: Controlling eutrophication along the freshwatermarine continuum: dual nutrient $(\mathrm{N}$ and $\mathrm{P})$ reductions are essential, Estuaries Coasts., 32, 593-601, 2009.

Paerl, H. W. and Otten, T. G.: Harmful cyanobacterial blooms: causes, consequences, and controls, Micro. Ecol., 65, 995-1010, 2013

Parliamentary Commissioner for the Environment: Restoring the Rotorua lakes: The ultimate endurance challenge, Wellington, New Zealand, 50 pp., 2006.

Peryer-Fursdon, J., Abell, J. M., Özkundakci, D., Hamilton, D. P., and Pearson, L.: Spatial variability in sediment phosphorus characteristics along a hydrological gradient upstream of Lake Rotorua, New Zealand, Environ. Earth Sci., 73, 1573-1585, 2015.

Reynolds, C. S.: The Ecology of Phytoplankton, Cambridge University Press, Cambridge, UK, 552 pp., 2006.

Rutherford, J. C., Pridmore, R. D., and White. E.: Management of phosphorus and nitrogen inputs to Lake Rotorua New Zealand, J. Water Res. Pl. ASCE, 115, 431-439, 1989.
Rutherford, J. C., Dunmov, S. M., and Ross, A. H.: Predictions of phosphorus in Lake Rotorua following load reductions, NZ J. Marine Freshw. Res., 30, 383-386, 1996.

Schindler, D. W., Hecky, R. E, Findlay, D. L., Stainton, M. P., Parker, B. R., Paterson, M. J., Beaty, K. G., Lyng, M., and Kasian, S. E.: Eutrophication of lakes cannot be controlled by reducing nitrogen input: results of a 37-year whole-ecosystem experiment, PNAS, 105, 11254-11258, 2008.

Smith, V. H: Low nitrogen to phosphorus ratios favor dominance by blue-green algae in lake phytoplankton, Science, 4611, 669-671, 1983.

Smith, V. H., Willén, E., and Karlsson, B.: Predicting the summer peak biomass of four species of blue-green algae (cyanophyta/cyanobacteria) in Swedish lakes, JAWRA, 23: $397-$ $402,1987$.

Smith, V. H., Wood, S. A., McBride, C. G., Atalah, J. Hamilton, D. P., and Abell, J. M.: Phosphorus and nitrogen loading restraints are essential for successful eutrophication control of Lake Rotorua, New Zealand, Inland Waters, 6, 273-283, 2016.

Tempero, G.: Ecotoxicological Review of Alum Applications to the Rotorua Lakes. Environmental Research Institute Report 52, University of Waikato, Hamilton, 37 pp., available at: http: //www.rotorualakes.co.nz/vdb/document/1283 (last access: 19 March 2016), 2015

Tempero, G., McBride, C., Abell, J., and Hamilton, D.: Anthropogenic Phosphorus Loads to Lake Rotorua. Environmental Research Institute Report 66, University of Waikato, Hamilton, 31 pp., available at: http://www.waikato.ac.nz/eri/research/ publications (last access: 10 June 2016), 2016.

Timperley, M. H.: Phosphorus in spring waters of the Taupo Volcanic Zone, North Island, New Zealand, Chem. Geol., 38, 287386, 1983.

Vrede, T., Ballantyne, A., Mille-Lindblom, C., Algesten, G., Gudasz, C., Lindahl, S., and Brunberg, A. K.: Effects of N : P loading ratios on phytoplankton community composition, primary production and $\mathrm{N}$ fixation in a eutrophic lake, Freshw. Biol., 54, 331-344, 2009.

Williamson, R. B., Smith, C. M., and Cooper, A. B.: Watershed riparian management and its benefit to a eutrophic lake, J. Water Res. Pl. ASCE, 122, 24-32, 1996. 